\title{
Discussion on Fine Characterization Technology of Single Sand Body in Fluvial Reservoir
}

\author{
Mei Xu \\ Geological Institute of the Fourth Oil Production Plant of Daqing Oilfield Co., Ltd, Daqing, Heilongjiang, 163511, China
}

\begin{abstract}
Fuyu oil layer of an oilfield is an ultra-low permeability oil layer. The remarkable characteristics of this oil layer are poor physical properties, low single well production, 2-4 layers of sand body longitudinally, large change frequency of plane upper layer and continuous characteristics. In order to realize effective oil layer development and ensure effective reservoir utilization. According to the poor physical properties of this oilfield, this paper analyzes the microscopic and macroscopic responsiveness of the reservoir, ensures effective permeability and thickness of permeable sand body, quantificationally depicts the plane distribution of permeable sand body, and effectively determines the distribution range of the reservoir according to the description of single sand body, thus providing a good technical means for subsequent scale production.
\end{abstract}

Keywords: Rivers, Reservoir, Description of single sand body, Sand seepage characterization.

\section{Introduction}

The structure of an oil field is located in the syncline axis and East Wing of the central depression area of the basin. The main purpose of development is Fuyu oil layer, which is characterized by poor reservoir physical properties and low single well productivity, which is very unfavorable to the development of the oil field [1-3]. Therefore, in order to ensure the productivity and realize the utilization of oilfield resources, it is necessary to strengthen the use of fine characterization technology of single sand body in fluvial reservoirs, strengthen the research on related rockelectricity relationship, realize quantitative characterization of permeable sand body, promote the promotion of local resource development potential, and lay a foundation for the improvement of economic benefits in this area.

\section{Define reservoir permeability}

The productivity of an oil well in an oil field is affected by many factors, among which the most important ones are sand microfacies, reservoir physical properties and oil-bearing property of oil layers. The related research on microscopic throat characteristics shows that the reservoir has different characteristics even at different throat positions of the same hole position, and there are significant differences between throat radii of different permeability levels, while the differences between pore radii are relatively small. Therefore, strengthening the control of throat radius is of key significance to enhance the permeability of reservoirs, and it is also the only factor that can be controlled. By strengthening the analysis of the relationship between throat radius and drainage pressure, the throat radius can be kept less than $0.24 \mu \mathrm{M}$, the displacement pressure can increase significantly [4-5]. If there is a good linear relationship between throat radius and permeability, the throat radius can be kept at $0.24 \mu$ $\mathrm{M}$, the permeability can reach $0.2 \mathrm{md}$, so it is necessary to scientifically control the throat radius, so as to effectively improve the development potential of the reservoir. Therefore, when studying reservoir parameters, fully realize the integration of linear data, grasp the relationship between core and electrical logging curve, reasonably calculate permeability, realize the image description of sand body, clarify the reservoir distribution, and provide an effective basis for subsequent oilfield exploitation. 


\section{Quantitative characterization of permeable sand bodies in ultra-low permeability reservoirs}

The information characteristic of ultra-low permeability reservoir is thin interbedded sand and mudstone, and the shale content of this layer is relatively high, which has a great impact on the characterization of permeability. Therefore, in the characterization, it is necessary to use the traditional method to separately respond to the acoustic time difference and express the properties of reservoir objects. Therefore, in the implementation of quantitative characterization, it is necessary to use the relative value of natural gamma to fully reflect the reservoir lithology, so as to scientifically calculate the permeability. In practical research, it is necessary to give priority to strengthening the analysis of natural gamma relative value on acoustic time difference, so as to scientifically correct mudstone and reconstruct the permeability calculation method of acoustic time difference. Because the shale content of the reservoir in the study area is obviously higher than that in other areas, and the calcium content is also higher, it is necessary to use the relative values of acoustic time difference and natural gamma ray respectively for calculation. Attention should also be paid to the high shale content or large deviation under other circumstances. If the acoustic difference under high shale content is large, it may be due to the influence of high calcareous condition to a great extent, and the relative value of natural gamma ray at this time will be higher than the normal level, so the shale content calculated by using the relative value of acoustic time difference and natural gamma ray will be higher, and the permeability value will become larger.Therefore, in the detailed theoretical calculation, it is necessary to follow the relevant ideas and correct the amount of mudstone according to the relative acoustic value, so as to reconstruct the acoustic time difference curve, reduce the impact of mud on mining and achieve good permeability. Firstly, the core depth homing value can be calculated according to the actual situation of mining, so as to ensure that the influence on acoustic time difference can be corrected on the basis of calculating shale content. Because the mudstone time difference $\delta \Delta$ tsh is larger than the sandstone skeleton time difference $\delta$ TMA, the time difference $\delta \mathrm{T}$ is larger in terms of the measured results in muddy reservoirs, so the time difference $\delta \Delta \mathrm{te}$ after correction can be reflected in the following formula: $\triangle \mathrm{te}=\triangle \mathrm{t}-\mathrm{Vsh}(\triangle \mathrm{tsh}-\triangle \mathrm{tma})$

$$
\begin{aligned}
& \mathrm{Vsh}=\frac{2^{G C U R \cdot \triangle G R-1}}{2^{G C U R-1}} \\
& \triangle \mathrm{GR}=\frac{G R-G R_{\text {min }}}{G R_{\text {max }}-G R_{\text {min }}}
\end{aligned}
$$

Vsh_-Clay content, f;

$\triangle \mathrm{GR}$ — natural gamma relative index, $\mathrm{f}$;

GCUR — Hilchie index, no unit;

GR — The natural gamma value of the target layer, API; GRmax — the natural gamma value of pure mudstone, API;
GRmin — The natural gamma value of pure sandstone, API.

When analyzing acoustic data, it is necessary to analyze the porosity and corrected acoustic moveout of the core to analyze the core permeability, so as to establish a scientific fitting model and construct the porosity and permeability formula. Subsequently, through the mudstone correction of acoustic moveout, the impact on calcareous and mudstone is minimized to ensure the improvement of correlation fitting coefficient. Of course, comparative analysis can be carried out in this process to ensure the orderliness of multi-well evaluation results. By using this method, the effectiveness of permeability can be more scientifically ensured, the coincidence degree of core analysis can be ensured, the microscopic and macroscopic seepage capacity of the reservoir can be deeply embodied in detail, and the expression of correlation can be realized. If the bellowing radius is $>$ $0.24 \mu \mathrm{m}$ and $\mathrm{k}>0.2 \mathrm{md}$, it can represent the production limit of ultra-low permeability reservoirs in this oilfield. In this process, using direct software for analysis can ensure the information extraction in the reservoir with permeability $>0.2 \mathrm{md}$, and then draw the distribution map under the control of corresponding lithofacies to ensure the distribution characteristics of sand body plane, so as to effectively describe and identify the permeability.

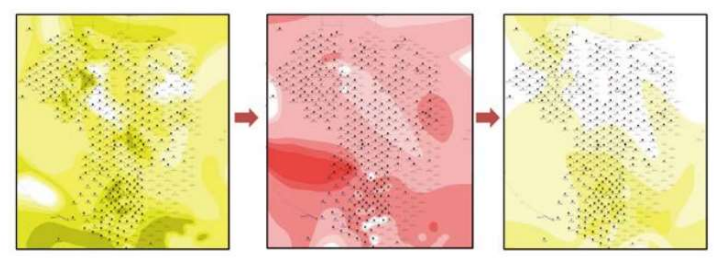

Fig. 1. Depiction map of permeable sand body in an oilfield 


\section{Analysis of fine characterization of single sand body in reservoir}

Fuyu oil layer in this oilfield belongs to multi-stage superimposed channel sand body deposition, which is characterized by strong heterogeneity. In practical research, only by perfect single-stage channel characterization can the longitudinal superimposed relationship of reservoirs be better ensured and the stability of reservoir boundaries be ensured. First, the electrical logging curves can be used to analyze the morphological and rhythmic characteristics. If conditions permit, Fuyu oil layer can be divided into 22 stages of single sand bodies in detail, and then the structure of sand bodies can be identified according to core and logging data. Of course, the division and correlation of multiple unit strata can also be realized by means of facies control and skeleton section closure. Then, according to the characteristics of electrical logging curve of single sand body, the identification attributes of different standards are established [6-7]. In this process, it is necessary to analyze various single-stage channel analysis methods such as "morphological difference", "rhythm difference" and "amplitude difference" according to the dense well pattern data, study the distribution state of well control area, guide the distribution of sedimentary microfacies in low well control area, complete the plane depiction of sedimentary microfacies of single sand body in multiple periods, and control the width of channel sand body in the range of $500 \sim 1000 \mathrm{~m}$.

\section{Identification and application of braided river single sand body}

Shallow sandy braided river, because the river channel is often changed, in the underground braided river reservoir, only the last braided river channel before abandonment can be identified. During the flood period, the river channel will be submerged, so a single river channel will be formed. In the falling period, it will emerge from the water surface and be reflected in the channel in the form of braiding, and then in the dry season, the river channel will become abandoned, but this river channel is usually very narrow. Therefore, the braided river of this style usually needs to be deposited in the way of "wide dam and narrow channel".

\subsection{Plane combination of braided and beach dams}

In order to accurately grasp the distribution of core beach dam and braided channel, it is necessary to clarify the differences between them, and then set obvious identification marks to distinguish core beach dam and braided channel.

\subsubsection{Filling style of braided river channel}

By observing the river outcrop and the core of coring wells in the study area, it is used to distinguish different filling styles: Sandy filling, argillaceous semi filling and argillaceous filling. Because of its different hydrodynamic performance, it shows a coarser vertical aggradation sand body. The vertical binary structure of the sand body is not very clear, but it still has strong positive rhythm characteristics, which is reflected in the bell shape on the curve.

\subsubsection{Identification and combination of beach dam}

For the identification mark of core beach dam, it is necessary to observe the vertical sequence and the relative depth of sand top. After confirming the relevant marks, it is necessary to scientifically divide the braided flow zone sand body and clarify the quantitative scale of typical core beach dam. Through the analysis of global satellite photos and the analysis of factors such as the width, length and width of Xintan dam, it is found that the relationship between them is positive correlation, so as to provide a good geological basis for subsequent oil exploitation.

\section{Conclusion}

To sum up, through the discussion of fine characterization technology of single sand body in fluvial reservoir and the combination of micro and macro, it can be more clear that the throat radius is greater than $0.24 \mu \mathrm{m}$ and the permeability is greater than $0.2 \mathrm{mD}$, which is the lowest permeability reservoir development limit for oilfield exploitation. In this process, if mudstone is used for correction, a physical parameter model can be established by zoning, the technical process of quantitative characterization of permeable sand bodies can be described in detail, and scientific identification and characterization of high permeability strips can be done well. At the same time, through the anatomy of dense well pattern, we can establish a perfect river channel identification method, more clearly define the spatial distribution law of sedimentary sand body of Fuyu superimposed river channel sand body, analyze the identification and application of braided river single sand body through the characterization of permeable sand body and fine characterization of single sand body, effectively use reservoir identification technology, and clarify the development potential of the established area.

\section{References}

1. Lan Xue. Fine description technology of single sand body in fluvial tight reservoir[J]. Petroleum Knowledge, 2019(4): 38-39.

2. Zhang Pengkai, Yue Dali, Rong Chengrui. Application of "single sand body" modeling method based on configuration interface in fluvial facies reservoir configuration modeling [C]. The 15th National Paleogeography and Proceedings of the Academic Conference on Sedimentology. 2018:1-2. 
3. Chen Bo, Duan Dongping, Liu Yinghui, et al. Seismic sedimentology interpretation and sedimentary evolution analysis of middle-deep fluvial sand bodies in Xihu Depression[J]. China Offshore Oil and Gas, 2019, 31(3): 117-126.

4. He Yuhang, Wang Qingyu, Zhu Wei, et al. Prototype geological model of single sand body in underwater distributary channel based on dense well pattern [J]. Daqing Petroleum Geology and Development, 2018, 37(3): 43-48. Chinese.

5. Zhu Jinli. Quantitative description of remaining gas distribution and potential tapping strategies for strong heterogeneous tight sandstone gas reservoirs: Taking the northern old area of Block Su 11 in Sulige Gas Field as an example [J]. Natural Gas Industry, 2020, 40(11) :89-95.

6. Li Bing. Identification method of thin-bed sand connectivity[J]. West China Prospecting Engineering, 2019, 31(7): 71-75.

7. Li Hongye. Research and application of single sand body fine characterization technology [J]. China Chemical Industry Trade, 2020(24):248-249. 